\title{
Avaliação do perfil de sensibilidade de Escherichia coli isoladas de infecção do trato urinário aos antimicrobianos
}

\author{
Evaluation of the sensitivity profile of Escherichia coli isolated from urinary tract infection to \\ antimicrobials
}

Evaluación del perfil de sensibilidad de Escherichia coli aislada de infección del tracto urinario a los antimicrobianos

Recebido: 26/07/2021 | Revisado: 30/07/2021 | Aceito: 03/08/2021 | Publicado: 08/08/2021

Luisa Ferreira da Cruz

ORCID: https://orcid.org/0000-0001-6880-3596 University of São João del-Rei, Brazil

E-mail: luisaferreiradacruz@gmail.com

Israel Lucas Antunes Souza

ORCID: https://orcid.org/0000-0002-6177-5059

University of São João del-Rei, Brazil

E-mail: israellasouza@gmail.com

Larissa Dias de Souza

ORCID: https://orcid.org/0000-0003-3598-5842 University of São João del-Rei, Brazil

E-mail: larissa6000@hotmail.com

Nubia da Silva Cardoso

ORCID: https://orcid.org/0000-0002-1555-9478 University of São João del-Rei, Brazil E-mail: nubiascardoso@ @otmail.com

Carlos Ananias Aparecido Resende

ORCID: https://orcid.org/0000-0003-1310-408X University of São João del-Rei, Brazil E-mail: carlosresende.farmaceutico@gmail.com

Gustavo Nogueira Coelho

ORCID: https://orcid.org/0000-0003-0579-3356 University of São João del-Rei, Brazil

E-mail: gustavonogueiracoelho@ hotmail.com

Marcelo Gonzaga de Freitas Araújo

ORCID: https://orcid.org/0000-0003-3032-2556 University of São João del-Rei, Brazil E-mail:mgfaraujo@ufsj.edu.br

\begin{abstract}
Resumo
O agente etiológico mais comumente isolado das infecções do trato urinário (ITUs) é a bactéria Escherichia coli (E. coli), a qual é responsável por cerca de $40 \%$ dos casos. Sendo microrganismos Gram-negativos, as E. coli possuem uma parede celular complexa, motivo pelo qual alguns antibióticos são menos eficazes quando comparados com sua com sua ação contra bactérias Gram-positivas. Diante disso, o objetivo deste trabalho é avaliar o perfil de sensibilidade de amostras clínicas de bactérias $E$. coli aos antimicrobianos usados no tratamento da ITU através do teste de difusão em ágar. Após a coleta e análise dos dados foi possível observar que a maioria dos isolados clínicos apresentou resistência a amoxicilina e foram mais sensíveis a nitrofurantoína e a cloranfenicol. A partir das informações obtidas após a análise dos dados foi possível observar que apesar do rígido controle da administração de medicamentos antimicrobianos, a incidência de bactérias resistentes a tais medicamentos é alarmante.
\end{abstract}

Palavras-chave: Antimicrobianos; Escherichia coli; Infecção do trato urinário; Resistência; Teste de sensibilidade.

\begin{abstract}
The most commonly isolated etiologic agent of urinary tract infections (UTIs) is the bacterium Escherichia coli (E. coli), which accounts for about $40 \%$ of cases. As Gram-negative microorganisms, E. coli have a complex cell wall, which is why some antibiotics are less effective when compared to their action against Gram-positive bacteria. Therefore, the objective of this work is to evaluate the sensitivity profile of clinical samples of $E$. coli bacteria to antimicrobials used in the treatment of UTI through the agar diffusion test. After data collection and analysis, it was possible to observe that most clinical isolates were resistant to amoxicillin and were more sensitive to nitrofurantoin and chloramphenicol. From the information obtained after analyzing the data, it was possible to observe that despite
\end{abstract}


the strict control of the administration of antimicrobial drugs, the incidence of resistant bacteria to such drugs is alarming.

Keywords: Antimicrobials; Escherichia coli; Resistance; Sensibility test; Urinary Tract infection.

\section{Resumen}

El agente etiológico más comúnmente aislado de las infecciones del tracto urinario (ITU) es la bacteria Escherichia coli (E. coli), que representa alrededor del $40 \%$ de los casos. Como microorganismos Gram-negativos, E. coli tiene una pared celular compleja, razón por la cual algunos antibióticos son menos efectivos en comparación con su acción contra las bacterias Gram-positivas. Por tanto, el objetivo de este trabajo es evaluar el perfil de sensibilidad de muestras clínicas de la bacteria E. coli a los antimicrobianos utilizados en el tratamiento de las ITU a través de la prueba de difusión en agar. Después de la recopilación y el análisis de los datos, fue posible observar que la mayoría de los aislados clínicos eran resistentes a la amoxicilina y más sensibles a la nitrofurantoína y al cloranfenicol. De la información obtenida luego del análisis de los datos se pudo observar que a pesar del estricto control de la administración de antimicrobianos, la incidencia de bacterias resistentes a dichos fármacos es alarmante.

Palabras clave: Antimicrobianos; Escherichia coli; Infección del tracto urinário; Prueba de sensibilidade; Resistencia.

\section{Introdução}

A infecção do trato urinário (ITU) é definida como a presença e proliferação de cepas patogênicas de bactérias ou outros microrganismos que colonizem e causem dano ao urotélio, que é o epitélio responsável por recobrir o trato urinário (Michel et al., 2021). Trata-se de uma afecção muito comum em âmbito hospitalar e comunitário, estimando-se que existam 150 milhões de casos anuais em todo o mundo (Flores-Mireles et al., 2015). Em recém-natos, é mais comum no sexo masculino (por complicações de malformações congênitas), passando a acometer mais o sexo feminino a partir da idade escolar (mantendo esse padrão epidemiológico desde o início da vida sexual até o período em que as mulheres se encontram majoritariamente na menopausa), voltando a ser mais incidente dentre homens após os 50 anos, devido a complicações prostáticas (Wang et al., 2018). Diversos fatores predispõem as mulheres a serem as mais atingidas por essa patologia, dentre os quais são notáveis a anatomia geniturinária feminina e o uso de alguns anticoncepcionais que podem alterar a microbiota genital, favorecendo a colonização por patógenos oportunistas sendo que, esses microrganismos podem contaminar todo o trato urinário, podendo causar pielonefrite ou glomerulonefrite, caso não haja um tratamento adequado (Geerlings, 2016). As ITUs podem ser classificadas de acordo com a localização anatômica: vias baixas (cistite, uretrite, epididimite, orquite e prostatite) e vias altas, que são as pielonefrites (Kaufman et al., 2019).

Cerca de $90 \%$ dos casos de ITU são causados por Enterobacterias, sendo que 85 a 90\% dessas infecções, o agente mais frequentes é a Escherichia coli uropatogênica (McLellan \& Hunstad, 2016; Moura \& Fernandes, 2010). A E. coli é um bacilo Gram-negativo pertence à família das Enterobacteriaceae. Habita naturalmente o lúmen intestinal dos seres humanos, ocorrendo simbiose entre o organismo humano e essas bactérias, fazendo parte da flora intestinal natural. No entanto, pode vir a causar infecção quando alcança as vias urinárias (Leimbach et al., 2013; McLellan \& Hunstad, 2016)

A antibioticoterapia, segundo a Organização Mundial de Saúde (OMS), somente deveria ser iniciada após a identificação da bactéria e do seu respectivo antibiograma, no entanto, na prática clínica, isso não ocorre, sendo que o paciente inicia uma terapia empírica, com base na experiência adquirida acerca das ITU (Koch et al., 2008). Os antibióticos mais comumente utilizados são as fluoroquinolonas, sendo o norfloxacino um dos fármacos mais utilizados, o qual apresenta boa ação sobre microrganismos Gram-negativos, incluindo a E. coli (Lee et al., 2018) . Para que o tratamento empírico seja realizado com maior êxito, um estudo epidemiológico do agente patogênico pode auxiliar no melhor antibiótico a ser utilizado (de Cueto et al., 2017). Só se poderá continuar a realizar tratamentos empíricos se os microrganismos forem sistematicamente analisados, monitorizando-se seu padrão de comportamento frente aos antibióticos (José Barbas Rodrigues \& Paula Dias Barroso, 2011). 
À medida que cepas de E. coli e outros patógenos Gram-negativos vem se tornando resistentes a associação de sulafametoxazol/trimetoprima, as fluoroquinolonas estão sendo cada vez mais utilizadas como terapia empírica de infecções das vias urinarias (Carlsen et al., 2019). O uso excessivo e inapropriado desses agentes está limitando sua utilidade clínica. Atualmente, fluoroquinolonas mais novas e potentes estão sendo desenvolvidas, as quais apresentam maior atividade contra microrganismos Gram-positivos e Gram-negativos, incluindo algumas cepas resistentes as quinolonas (Flores-Mireles et al., 2015).

A nitrofurantoína é um composto que inibe vários sistemas enzimáticos bacterianos, incluindo a acetilcoenzima $\mathrm{A}$, agindo também, de modo a interromper a síntese da parede celular das bactérias, sendo que seu espectro de ação compreende a E. coli e a Enterococos, tendo pouca ação sobre Proteus, Pseudomonas, Enterobacter e Klebsiella (Huttner et al., 2015).

O cloranfenicol possui um mecanismo de ação que consiste na inibição da síntese proteica bacteriana, possuindo amplo espectro de atividade antimicrobiana, incluindo microrganismos Gram-negativos e Gram-positivos. A resistência pode ser adquirida através de plasmídeos ou de alterações de permeabilidade do fármaco. Mais frequentemente, a resistência é determinada pela produção de uma enzima, acetiltransferase ou nitrorredutase, que inativa o composto (Huttner et al., 2015).

A amoxicilina é uma penicilina semissintética derivada da ampicilina e ambas apresentam as mesmas propriedades antimicrobianas e farmacocinéticas, exceto pela melhor absorção oral da amoxicilina. É bastante estável em meio ácido e é inativada por beta-lactamases, originando derivados do ácido penicilóico desprovidos de ação antimicrobiana (de Velde et al., 2016). O mecanismo mais frequente de resistência aos antibióticos beta-lactâmicos é a produção de enzimas do tipo betalactamase, as quais são codificadas em genes cromossômicos e plasmidiais e, embora sejam distintas por várias características físico-químicas e biológicas, o resultado final de ação é o mesmo: a hidrólise do anel beta-lactâmico, destruindo a ação antimicrobiana dos antibióticos beta-lactâmicos (Flores-Mireles et al., 2015). Com a finalidade de bloquear a ação das betalactamases, foram desenvolvidas substâncias capazes de inibir sua ação, os chamados inibidores de beta-lactamases, os quais, assim, mantem a ação dos antibióticos beta-lactâmicos mesmo na presença das enzimas beta-lactamases (Krauß \& Bracher, 2018).

A resistência antimicrobiana tem aumentado em todo o mundo, gerando dificuldades no controle de infecções e contribuindo para o aumento dos custos do sistema de saúde e dos próprios hospitais (Thabit et al., 2015). O papel do farmacêutico é importante no controle dos microrganismos resistentes a antibióticos, pois ele é o responsável por orientar os pacientes quanto ao uso correto de medicamentos, contribuindo para o uso racional de antibióticos, o que pode contribuir para o combate a resistência bacteriana.

\section{Metodologia}

Este trabalho é uma pesquisa experimental, com abordagem quantitativa (Pereira et al., 2018) que teve como objetivo avaliar o perfil de sensibilidade de amostras clínicas de bactérias aos antimicrobianos usados no tratamento da ITU através do teste de difusão em ágar.

\subsection{Microrganismos}

Para este estudo, foram utilizadas 40 isolados clínicos de E. coli identificadas após a realização das provas usuais de identificação de bacilo gram-negativo (BGN), fornecidos pela Seção de Microbiologia do Laboratório Cemas - Centro Municipal de Apoio a Saúde, em Divinópolis-MG e mais 08 amostras fornecidas pelo laboratório Clinlab, também localizado em Divinópolis. Foi incluída, também, a cepa padrão de $E$. coli ATCC 8937. Os isolados clínicos foram denominados EC ( $E$. coli) seguido de Numeração indicativa de cada região de coleta referente à respectiva amostra. As amostras foram mantidas em estoque em tubo inclinado contendo Agar Muller Hinton (MHA) sobre refrigeração até o momento do preparo dos inóculos. 


\subsection{Discos de Antibiograma}

Os discos de papel contendo antibióticos utilizados neste estudo foram obtidos comercialmente do Laboratório CECON (Centro de Controle e Produtos para Diagnósticos Ltda - São Paulo), sendo esses: amoxicilina (AMO) 10mcg, amoxicilina + clavulânico (AMC) 30mcg e sulfametoxazol + trimetoprima (SMT+TMP) 25mcg, e do DME (Diagnósticos Microbiológicos Especializados - São Paulo), sendo: norfloxacino (NOR) 10mcg, cloranfenicol (CLO) 30mcg e nitrofurantoína (NIT) 300mcg.

\subsection{Padronização da Suspensão Microbiana}

Cultivos de 48 horas dos isolados clínicos de E. coli em Caldo Muller Hinton (MHC) foram transferidos para solução salina $0,9 \%$ e ajustada a turbidez até a escala $0,5 \mathrm{de} \mathrm{McFarland}\left(10^{8} \mathrm{UFC} / \mathrm{mL}\right)$, que foi confirmada por leitura espectrofotométrica a $620 \mathrm{~nm}$ com valor de absorbância entre 0,08 a 0,10 que foi, então, utilizada nos testes.

\subsection{Determinação da sensibilidade aos antimicrobianos}

O teste de sensibilidade antimicrobiana foi realizado por meio da técnica de difusão em ágar de acordo com a metodologia descrita segundo a norma M7-A6 do Clinical and Laboratory Standards Institute (Leão et al., 2018). O teste de difusão em ágar foi realizado em placas de petri com meio ágar Muller Hinton. As bactérias foram suspensas em solução salina e semeadas no meio de cultura. Os discos contendo os antibióticos amoxicilina, sulfametoxazol+trimetoprima, amoxicilina+clavulanato, norfloxacino, nitrofurantoína e cloranfenicol foram depositados, assepticamente, sobre o ágar inoculado, mantendo uma distância de $15 \mathrm{~mm}$ da borda. A placa invertida foi incubada em estufa à temperatura de $37^{\circ} \mathrm{C}$ durante $24 \mathrm{~h}$. O diâmetro da zona de inibição foi mensurado com auxílio de um paquímetro para a determinação da susceptibilidade. O mesmo procedimento foi realizado utilizando a cepa de E. coli ATCC 8937 para controle de sensibilidade do teste. Todos os testes foram realizados em duplicata.

\subsection{Interpretação dos halos de inibição: definição qualitativa de sensibilidade das amostras aos antimicrobianos}

Considerou-se para a análise qualitativa de susceptibilidade das bactérias aos antimicrobianos testados, as extensões dos diâmetros dos halos inibitórios gerados por cada um dos fármacos (Leão et al., 2018).

\section{Resultados}

Os valores médios dos halos de inibição obtidos no teste de sensibilidade de E.coli aos antimicrobianos estão apresentados na Tabela 1. Observa-se que 28 amostras apresentaram resistência à amoxicilina, 24 à associação sulfametoxazol/trimetoprima, 21 ao norfloxacino, 10 ao cloranfenicol e 3 à nitrofurantoína. Apenas a amostra 69578 não apresentou formação de halo de inibição a nenhum dos fármacos testados, sendo, portanto, a única amostra com resistência aos seis antimicrobianos testados: amoxicilina, sulfametoxazol+trimetoprima, norfloxacino, cloranfenicol, amoxicilina+clavulanato e nitrofurantoína. Amostras que demonstraram resistência à amoxicilina foram testadas posteriormente com amoxicilina+clavulanato, tendo sido, todas as 28 amostras, sensíveis ao antibiótico. 
Tabela 1 - Valores médios dos halos de inibição obtidos no teste de sensibilidade aos antimicrobianos.

\begin{tabular}{|c|c|c|c|c|c|c|}
\hline \multirow{2}{*}{ AMOSTRAS } & \multicolumn{6}{|c|}{ Diâmetro dos Halos (mm) } \\
\hline & AMO & SMT+TMP & NOR & NIT & CLO & AMO \\
\hline EC 1 & 20 & 26 & 9 & 24 & 9 & 0 \\
\hline EC 2 & 20 & 26 & 9 & 25 & 0 & 0 \\
\hline EC 3 & 20 & 26 & 30 & 24 & 24 & 0 \\
\hline EC 4 & 19 & 26 & 8 & 20 & 0 & 0 \\
\hline EC 5 & 18 & 25 & 32 & 26 & 23 & 0 \\
\hline EC 6 & 19 & 26 & 27 & 26 & 21 & 0 \\
\hline EC 7 & 18 & 25 & 26 & 25 & 21 & 0 \\
\hline EC 8 & 19 & 26 & 21 & 24 & 20 & 0 \\
\hline 67712 & 0 & 0 & 33 & 23 & 30 & 0 \\
\hline 67588 & 25 & 28 & 31 & 23 & 26 & 0 \\
\hline 62445 & 26 & 30 & 35 & 23 & 28 & 0 \\
\hline 67655 & 23 & 29 & 34 & 23 & 30 & 0 \\
\hline 67637 & 21 & 25 & 25 & 20 & 25 & 0 \\
\hline 62585 & 0 & 20 & 0 & 24 & 31 & 0 \\
\hline 67593 & 0 & 0 & 22 & 21 & 31 & 0 \\
\hline 59383 & 0 & 0 & 0 & 20 & 26 & 0 \\
\hline 70083 & 0 & 23 & 32 & 21 & 25 & 0 \\
\hline 71881 & 0 & 0 & 23 & 19 & 23 & 0 \\
\hline 72089 & 18 & 25 & 30 & 19 & 23 & 0 \\
\hline 61295 & 23 & 0 & 28 & 25 & 30 & 0 \\
\hline 70075 & 0 & 0 & 0 & 22 & 0 & 0 \\
\hline 70124 & 20 & 26 & 35 & 24 & 30 & 0 \\
\hline 59387 & 0 & 0 & 0 & 23 & 25 & 0 \\
\hline 72021 & 0 & 0 & 11 & 12 & 18 & 0 \\
\hline 70037 & 0 & 0 & 16 & 20 & 25 & 0 \\
\hline 66680 & 24 & 19 & 11 & 20 & 20 & 0 \\
\hline 66572 & 22 & 18 & 25 & 20 & 23 & 0 \\
\hline 64751 & 0 & 0 & 0 & 22 & 23 & 0 \\
\hline 61230 & 21 & 23 & 25 & 18 & 30 & 0 \\
\hline 72011 & 0 & 0 & 0 & 21 & 27 & 0 \\
\hline 58937 & 20 & 0 & 21 & 23 & 21 & 0 \\
\hline 70031 & 0 & 0 & 28 & 19 & 22 & 0 \\
\hline 66115 & 0 & 0 & 24 & 23 & 29 & 0 \\
\hline 71590 & 23 & 22 & 30 & 24 & 32 & 0 \\
\hline 70039 & 0 & 0 & 0 & 18 & 19 & 0 \\
\hline 66910 & 0 & 19 & 21 & 22 & 28 & 0 \\
\hline 62796 & 0 & 0 & 0 & 21 & 0 & 0 \\
\hline 61142 & 0 & 0 & 0 & 22 & 26 & 0 \\
\hline 69578 & 0 & 0 & 0 & 0 & 0 & 0 \\
\hline 68993 & 0 & 0 & 0 & 16 & 0 & 0 \\
\hline 62646 & 0 & 21 & 25 & 17 & 29 & 0 \\
\hline 61993 & 0 & 21 & 26 & 17 & 30 & 0 \\
\hline 64941 & 0 & 0 & 26 & 18 & 27 & 0 \\
\hline 64952 & 0 & 0 & 0 & 20 & 0 & 0 \\
\hline 69578 & 0 & 0 & 0 & 20 & 0 & 0 \\
\hline 62601 & 0 & 23 & 0 & 20 & 27 & 0 \\
\hline 69072 & 24 & 0 & 0 & 11 & 0 & 0 \\
\hline ATCC 8739 & 0 & 0 & 33 & 20 & 30 & 0 \\
\hline
\end{tabular}

Fonte: Acervo da pesquisa.

Levando-se em conta os parâmetros estabelecidos, foi possível classificar, a partir da medida dos halos de inibição, as amostras que apresentaram sensibilidade, sensibilidade intermediária e resistência aos antimicrobianos. Os resultados do perfil de resistência de E.coli aos antimicrobianos estão apresentados na Figura 1. Foi possível observar das 49 amostras analisadas, e dentre os fármacos utilizados, a nitrofurantoína foi aquele que apresentou melhores resultados no teste de resistência, sendo 
que apenas 6,1\% apresentaram resistência. A amoxicilina é um resultado alarmante, pois 57,1\% das amostras demonstraram resistência, enquanto 48,9\% foram resistentes a sulfametoxazol/trimetoprima, 42,8\%, a norfloxacino e 20,4\%, ao cloranfenicol. Não foi observada resistência à combinação amoxicilina+clavulanato.

Figura 1: Resultado do perfil de resistência das cepas de E. coli aos antimicrobianos.

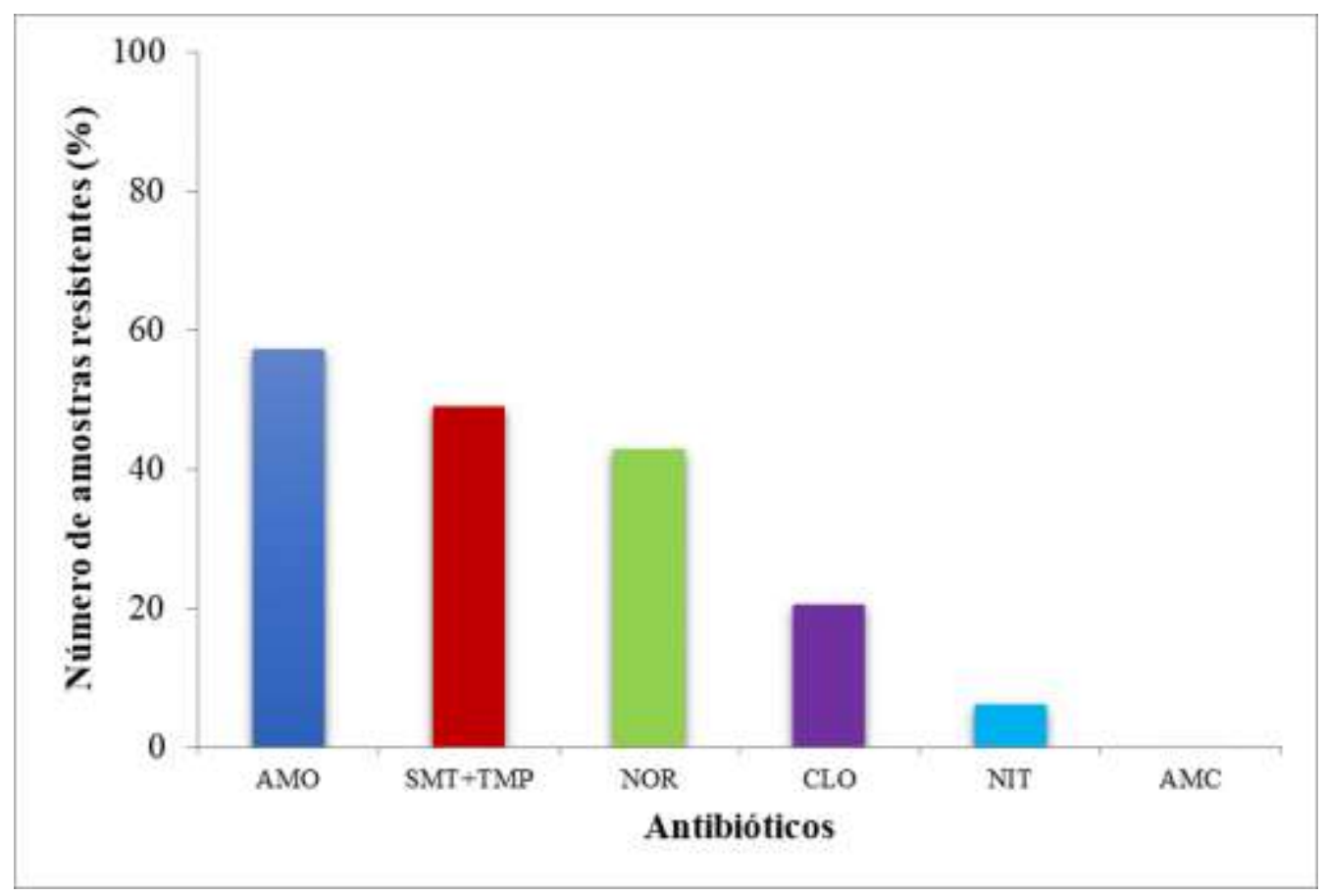

Fonte: Acervo da pesquisa.

As cepas de E. coli deste estudo mostraram-se mais resistentes à amoxicilina, e mesmo apresentando uma alta concentração urinária, este antimicrobiano não é recomendado para tratamento das ITUs por causa da resistência e por possível reincidência, se comparado a outros, sendo esta resistência justificada principalmente pela produção de beta-lactamase (Tandogdu \& Wagenlehner, 2016). Na atualidade, para uma boa resposta terapêutica nos casos de ITUs, deve utilizar a amoxicilina associada com o ácido clavulânico (Bono et al., 2021).

Na Figura 2, observam-se resultados em percentuais de amostras de E.coli sensíveis aos antibióticos. Das amostras testadas frente à combinação amoxicilina+clavulanato, todas apresentaram-se sensíveis. Em relação à nitrofurantoína sua sensibilidade foi de 93,9\%. Frente ao cloranfenicol, 79,6\% foram sensíveis. Em relação ao norfloxacino, 57,2\%, à associação sulfametoxazol+trimetoprima, 51,1\% apresentaram sensibilidade. A amoxicilina obteve a menor percentagem de sensibilidade, $42,9 \%$.

No trabalho realizado, obtiveram-se outros resultados com as 8 amostras que foram recolhidas de um laboratório particular. Elas foram submetidas aos mesmos testes de sensibilidade antimicrobiana já descritos. Os resultados obtidos dessas amostras apresentam uma implicação contrária às dos resultados das demais amostras coletadas na rede pública. Como resultado de antimicrobianos resistentes, têm-se: norfloxacino e cloranfenicol. Tais resultados encontram-se na Figura 2. 
Figura 2. Representação da sensibilidade das amostras.

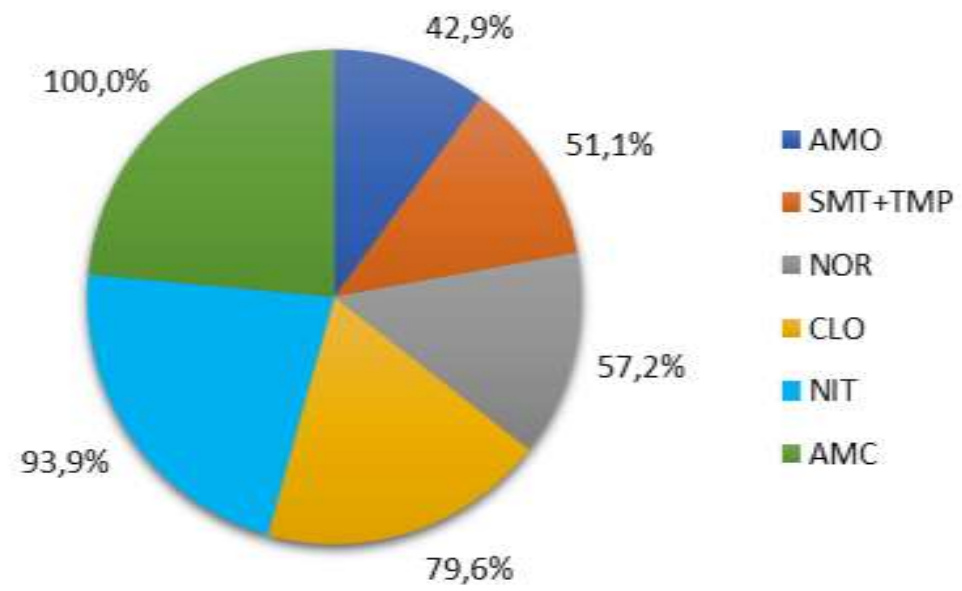

Fonte: Acervo da pesquisa.

É, ainda, possível associar a resistência à quantidade de antibióticos distribuídos gratuitamente pela rede pública de saúde, dados esses fornecidos pela SEMUSA (Secretaria Municipal de Saúde), conforme apresentado na Figura 3.

Figura 3. Quantidade de antibióticos distribuídos pelo sistema público de saúde de Divinópolis-MG.

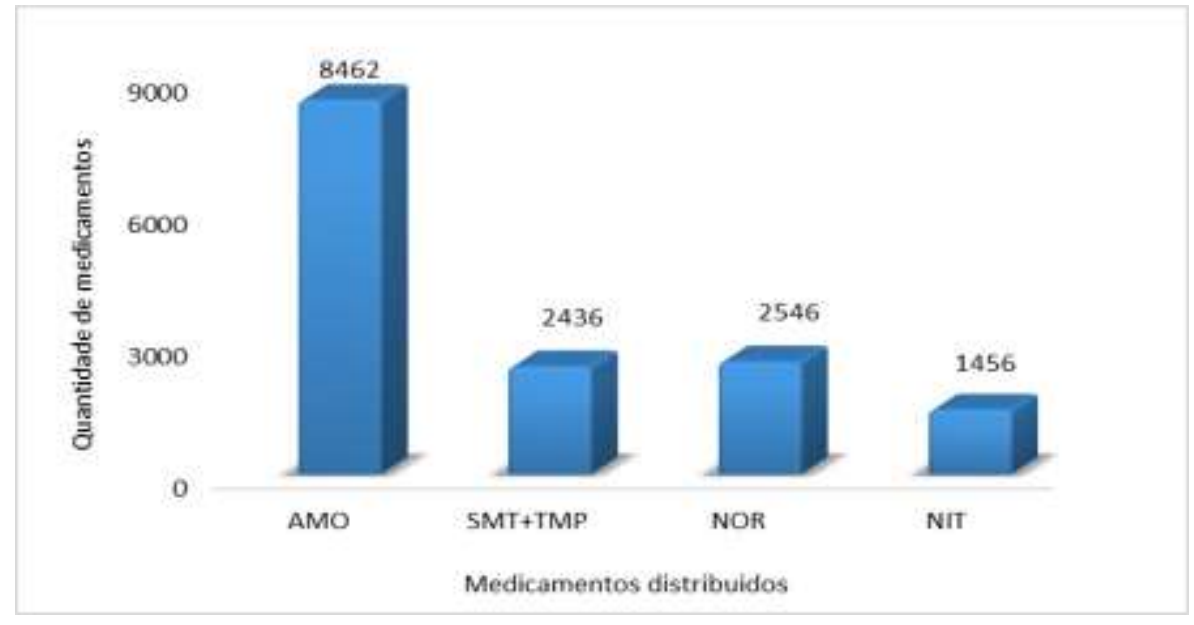

Fonte: Secretaria Municipal de Saúde (outubro/2013).

\section{Discussão}

A ITU é uma patologia frequente na clínica médica, sendo uma das causas que mais levam os pacientes à procura de auxílio médico. Aproximadamente 40 a 60\% das mulheres apresentam pelo menos um episódio de ITU em suas vidas, sendo que destas, metade apresentam episódios recorrentes (Bono \& Reygaert, 2017). No que se refere à etiologia, as Enterobactérias são as responsáveis pela maioria dos casos (McLellan \& Hunstad, 2016). Neste trabalho, as bactérias isoladas nas uroculturas foram testadas frente a uma série de antimicrobianos comumente prescritos pelos médicos.

A terapia empírica implica no uso de fármacos de amplo espectro, o que exige critério não só para trocar a terapia após o resultado da cultura, mas também na escolha da terapia inicial. O uso de múltiplos agentes antimicrobianos nos casos em que apenas uma terapia de menor espectro seria suficiente, expõe, inevitavelmente, o paciente a um risco aumentado de efeitos adversos e propicia a seleção de microrganismos cada vez mais resistentes (Bono \& Reygaert, 2017). 
O teste de sensibilidade aos antimicrobianos permite determinar a sensibilidade de determinada espécie bacteriana aos fármacos. A técnica de difusão em ágar é bastante utilizada, sendo considerada de fácil execução, reprodutível e permite a experimentação de diversos fármacos em uma mesma placa. O teste de sensibilidade a antimicrobianos representa um dos testes de maior importância clínica realizados na microbiologia (Campana et al., 2011). Devido ao grande número de antimicrobianos e à complexidade dos mecanismos de resistência desenvolvidos pelos microrganismos, é extremamente importante que haja uma avaliação constante da sensibilidade das bactérias aos fármacos na determinação do melhor tratamento com antimicrobianos (Hughes \& Andersson, 2017).

Neste estudo, 57,1\% dos isolados clínicos de E. coli apresentaram resistência ao antibiótico amoxicilina. Outros estudos analisaram a frequência de resistência de amostras clínicas de E. coli a amoxicilina. Paralikar et al., (2019), encontraram resistência à amoxicilina em 43,1\% das amostras isoladas de urina de pacientes infectados Erb et al., (2018), encontraram 98,85\% de amostras resistentes. A amoxicilina faz parte da relação nacional de medicamentos essenciais (RENAME), sendo disponível em cápsula e em solução. Como demonstrado neste trabalho, as prescrições de amoxicilina por parte dos médicos são exorbitantes em relação aos demais antibióticos, representando 56,79\% dos medicamentos que são distribuídos para tratamentos de ITU, ressaltando que amoxicilina possui um amplo espectro de ação, o que contribui para o resultado. No presente estudo, a amoxicilina foi o antibiótico que culminou em percentual superior de resistência. Por este fato, foi realizado o teste de suscetibilidade antimicrobiana nas amostras que apresentaram resistência frente à amoxicilina utilizando amoxicilina+clavulanato e assim as 28 amostras submetidas ao teste apresentaram sensibilidade ao antibiótico.

Em relação ao sulfametoxazol/trimetoprima, Estrada et al., (2016), justificam a elevada resistência por se tratar de um medicamento mais antigo, já há muito utilizado em infecções, possivelmente como automedicação e de maneira indiscriminada, levando a modificações cromossomiais bacterianas. A resistência ao sulfametoxazol/trimetoprima tem aumentado em todo o mundo, mesmo nas infecções comunitárias, limitando seu uso como antibiótico empírico. Desde o final da década de 80 já se observava uma notável diminuição na susceptibilidade dos uropatógenos para esses antimicrobianos. Nos Estados Unidos foi observado que entre os anos de 2003-2012 houve um aumento de 17,2\% para 22,2\% de cepas de E. Coli resistentes a sulfametoxazol/trimetoprima. Como está havendo um grande aumento de cepas resistentes, o uso de sulfametoxazol/trimetoprima já não é mais recomendado como tratamento empírico de pacientes com cistite não complicada ou pielonefrite (Bader et al., 2017). Em nosso estudo, a taxa de resistência foi de 48,9\%, comparando com o percentual da dispensação pública desse medicamento $(16,34 \%)$, sugerindo que sua resistência advém do tratamento empírico e do fato de que se trata de um medicamento mais antigo.

Dados sobre a resistência das fluoroquinolonas mostram que esses medicamentos estão ficando cada vez menos efetivos sobre E. coli, sendo que atualmente são consideradas drogas de segunda linha para o tratamento de cistite não complicada (Bader et al., 2017). O estudo realizado por (Lopes et al., 1998) já mostravam esse aumento, o que supõe o uso frequente desse antibiótico para a profilaxia de infecções e na terapia de ITU. A resistência à fluoroquinolona entre os patógenos urinários está em aumento tanto na comunidade como nos hospitais. Foi observado que a resistência da E.coli a ciprofloxacino em mulheres adultas que realizaram condutas ambulatoriais nos Estados Unidos aumentaram de 3,6\% para 11,8\% no período entre 2003-2012. Dentre as fluoroquinolonas prescritas na rede pública para tratamento de ITU, nota-se que o norfloxacino, com o percentual de 17,08\%, ocupa o segundo lugar dos antibióticos mais prescritos (Bader et al., 2017). Neste trabalho, encontramos $42,8 \%$ de amostras de E. coli resistentes ao norfloxacino. Portanto, o uso racional de antibióticos, respeitando dose e tempo de tratamento, e o conhecimento dos agentes mais frequentes e dos respectivos perfis de sensibilidade na comunidade são mandatórios, visto a necessidade de se evitar falhas terapêuticas e seleção de microrganismos resistentes (Pires et al., 2007).

A distribuição da nitrofurantoína no SUS ocupa o último lugar dos antibióticos prescritos pra ITU na rede pública, 
correspondendo a 9,77\%. Neste estudo, apenas $6,1 \%$ das amostras de E. coli apresentaram resistência à nitrofurantoína. Da mesma forma, Bail et al., (2006) apresentaram uma taxa de susceptibilidade de 95\%, sugerindo a nitrofurantoína como uma alternativa para o tratamento das ITU por microrganismos resistentes. A nitrofurantoína foi aprovada pelo FDA (Food and Drug Administration ) nos Estado Unidos em 1953, na qual tornou-se o padrão para a terapia de infecções do trato urinário (ITU) até o final da década de 1970, quando surgiram outros antibióticos como opções terapêuticas (Squadrito \& del Portal, 2017). No último Guidline da EAU (European Association of Urology) publicado em 2018 a nitrofurantoína foi recomendada como um dos fármacos de primeira linha para mulheres que estão apresentando um quadro de cistite não complicada (Erb et al., 2018). Estes resultados sugerem que as amostras resistentes à amoxicilina provavelmente são produtoras de beta-lactamase, visto que o clavulanato é inibidor dessa enzima.

\section{Conclusão}

Através da realização deste estudo, foi possível compreender a importância do teste de sensibilidade antimicrobiana, já que a elevada resistência das bactérias isoladas clinicamente aos antibióticos, demonstra que a prescrição correta é de suma importância para uma eficácia terapêutica, diminuindo, assim, casos recorrentes de infecção.

Percebeu-se, também, que a amoxicilina, foi o antibiótico com maior dispensação no SUS e também aquele que apresentou maior resistência a $E$. coli, o que leva à sugestão, neste caso, do tratamento com amoxicilina + clavulanato, o qual inibe a enzima lactamase. $\mathrm{O}$ antimicrobiano que apresentou maior sensibilidade foi a nitrofurantoína, tendo sido, consequentemente, o antibiótico menos prescrito na rede pública, seguido do cloranfenicol, que não faz parte do SUS.

Portanto, é de extrema importância o uso racional de antimicrobianos, respeitando a posologia e ter-se conhecimento dos parte dos prescritores do perfil de sensibilidade das bactérias causadoras, afim de evitar falhas terapêuticas e cepas resistentes. Por isso, é de fundamental importância o desenvolvimento de novos estudos que busquem conhecer as prevalências regionais dos uropatógenos, bem como seu perfil de resistência aos antimicrobianos. O conhecimento desses dados permite a comunidade médica escolher, entre as diversas alternativas terapêuticas, os antimicrobianos mais indicados para o tratamento empírico. Essas informações dão maior respaldo ao médico a fim de que se possa decidir a terapêutica antimicrobiana adequada

\section{Referências}

Bader, M. S., Loeb, M., \& Brooks, A. A. (2017). An update on the management of urinary tract infections in the era of antimicrobial resistance. Postgraduate Medicine, 129(2), 242-258. https://doi.org/10.1080/00325481.2017.1246055

Bail, L., Ito, C. A. S., \& Esmerino, L. A. (2006). Infecção do trato urinário: comparação entre o perfil de susceptibilidade e a terapia empírica com antimicrobianos. Rbac, 38(1), 51-56.

Bono, M. J., \& Reygaert, W. C. (2017). Urinary tract infection.

Bono, M. J., Reygaert, W. C., \& Doerr, C. (2021). Urinary Tract Infection (Nursing).

Campana, E. H., Carvalhaes, C. G., Barbosa, P. P., De Oliveira MacHado, A. M., De Paula, A. M., \& Gales, A. C. (2011). Avaliação das metodologias M.I.C.E. ${ }$, Etest ${ }^{\circledR}$ e microdiluição em caldo para determinação da CIM em isolados clínicos. Jornal Brasileiro de Patologia e Medicina Laboratorial, 47(2), 157-164. https://doi.org/10.1590/S1676-24442011000200011

Carlsen, S., Krall, S. P., Xu, K. T., Tomanec, A., Farias, D., \& Richman, P. (2019). Sensitivity of urinary pathogens for patients discharged from the emergency department compared with the hospital antibiogram. BMC Emergency Medicine, 19(1), 50. https://doi.org/10.1186/s12873-019-0264-z

de Cueto, M., Aliaga, L., Alós, J.-I., Canut, A., Los-Arcos, I., Martínez, J. A., Mensa, J., Pintado, V., Rodriguez-Pardo, D., Yuste, J. R., \& Pigrau, C. (2017). Executive summary of the diagnosis and treatment of urinary tract infection: Guidelines of the Spanish Society of Clinical Microbiology and Infectious Diseases (SEIMC). Enfermedades Infecciosas y Microbiologia Clinica (English Ed.), 35(5), 314-320. https://doi.org/10.1016/j.eimce.2017.03.021

de Velde, F., de Winter, B. C. M., Koch, B. C. P., van Gelder, T., \& Mouton, J. W. (2016). Non-linear absorption pharmacokinetics of amoxicillin: Consequences for dosing regimens and clinical breakpoints. Journal of Antimicrobial Chemotherapy, 71(10), 2909-2917. https://doi.org/10.1093/jac/dkw226

Erb, S., Frei, R., Tschudin Sutter, S., Egli, A., Dangel, M., Bonkat, G., \& Widmer, A. F. (2018). Basic patient characteristics predict antimicrobial resistance in 
E. coli from urinary tract specimens: a retrospective cohort analysis of 5246 urine samples. Swiss Medical Weekly, 148(4546), w14660. https://doi.org/10.4414/smw.2018.14660

Estrada, A., Wright, D. L., \& Anderson, A. C. (2016). Antibacterial antifolates: From development through resistance to the next generation. Cold Spring Harbor Perspectives in Medicine, 6(8), a028324. https://doi.org/10.1101/cshperspect.a028324

Flores-Mireles, A. L., Walker, J. N., Caparon, M., \& Hultgren, S. J. (2015). Urinary tract infections: Epidemiology, mechanisms of infection and treatment options. Nature Reviews Microbiology, 13(5), 269-284. https://doi.org/10.1038/nrmicro3432

Geerlings, S. E. (2016). Clinical presentations and epidemiology of urinary tract infections. Urinary Tract Infections: Molecular Pathogenesis and Clinical Management, 4(5), 27-40. https://doi.org/10.1128/9781555817404.ch2

Hughes, D., \& Andersson, D. I. (2017). Evolutionary Trajectories to Antibiotic Resistance. Annual Review of Microbiology, 71, 579-596. https://doi.org/10.1146/annurev-micro-090816-093813

Huttner, A., Verhaegh, E. M., Harbarth, S., Muller, A. E., Theuretzbacher, U., \& Mouton, J. W. (2015). Nitrofurantoin revisited: A systematic review and meta-analysis of controlled trials. Journal of Antimicrobial Chemotherapy, 70(9), 2456-2464. https://doi.org/10.1093/jac/dkv147

José Barbas Rodrigues, F., \& Paula Dias Barroso, A. (2011). Etiology and bacterial susceptibility to urinary tract infections. Revista Portuguesa de Saude Publica, 29(2), 123-131. https://doi.org/10.1016/S0870-9025(11)70016-5

Kaufman, J., Temple-Smith, M., \& Sanci, L. (2019). Urinary tract infections in children: An overview of diagnosis and management. BMJ Paediatrics Open, 3(1). https://doi.org/10.1136/bmjpo-2019-000487

Koch, C. R., Ribeiro, J. C., Schnor, O. H., Zimmermann, B. S., Müller, F. M., D’Agostin, J., Machado, V., \& Zhang, L. (2008). Resistência antimicrobiana dos uropatógenos em pacientes ambulatoriais, 2000-2004. Revista Da Sociedade Brasileira de Medicina Tropical, 41, $277-281$.

Krauß, J., \& Bracher, F. (2018). Pharmacokinetic enhancers (Boosters)—escort for drugs against degrading enzymes and beyond. Scientia Pharmaceutica, 86(4), 43. https://doi.org/10.3390/scipharm86040043

Leão, M. V. P., Tavares, T. A. A., Gonçalves e Silva, C. R., dos Santos, S. S. F., Junqueira, J. C., de Oliveira, L. D., \& Jorge, A. O. C. (2018). Lactobacillus rhamnosus intake can prevent the development of Candidiasis. Clinical Oral Investigations, 22(7), 2511-2518. https://doi.org/10.1007/s00784-018-2347-8

Lee, D. S., Lee, S. J., Choe, H. S., \& Giacobbe, D. R. (2018). Community-Acquired Urinary Tract Infection by Escherichia coli in the Era of Antibiotic Resistance. BioMed Research International, 2018. https://doi.org/10.1155/2018/7656752

Leimbach, A., Hacker, J., \& Dobrindt, U. (2013). E. coli as an all-rounder: The thin line between commensalism and pathogenicity. Current Topics in Microbiology and Immunology, 358, 3-32. https://doi.org/10.1007/82_2012_303

Lopes, A. A., Salgado, K., Martinelli, R., \& Rocha, H. (1998). Increase in the frequency of norfloxacin and ciprofloxacin resistance of bacteria isolated from urine culture. Revista Da Associação Médica Brasileira (1992), 44(3), 196-200. https://doi.org/10.1590/S0104-42301998000300006

McLellan, L. K., \& Hunstad, D. A. (2016). Urinary Tract Infection: Pathogenesis and Outlook. Trends in Molecular Medicine, $22(11), 946-957$. https://doi.org/10.1016/j.molmed.2016.09.003

Michel, P., Pereira, B., Regina, S., \& Souza, B. De. (2021). Prevalência e caracterização da infecção do trato urinário inferior em mulheres atendidas na atenção primária de saúde Prevalence and characterization of lower urinary tract infection in women met in health primary care. April, 37-42. https://doi.org/10.18378/rebes.v9i1.6170

Moura, L. B., \& Fernandes, M. G. (2010). A incidência de infecções urinárias causadas por E. coli. Revista Olhar Científico-Faculdades Associadas de Ariquemes, $1(2)$.

Paralikar, P., Ingle, A. P., Tiwari, V., Golinska, P., Dahm, H., \& Rai, M. (2019). Evaluation of antibacterial efficacy of sulfur nanoparticles alone and in combination with antibiotics against multidrug-resistant uropathogenic bacteria. Journal of Environmental Science and Health - Part A Toxic/Hazardous Substances and Environmental Engineering, 54(5), 381-390. https://doi.org/10.1080/10934529.2018.1558892

Pereira, A. S., Shitsuka, D. M., Parreira, F. J., \& Shitsuka, R. (2018). Metodologia da pesquisa científica.[e-book]. Santa Maria. Ed. UAB/NTE/UFSM. Disponível em: https://repositorio. ufsm. br/bitstream/handle ....

Pires, M. C. D. S., Frota, K. D. S., Martins, P. D. O., Correia, A. F., Cortez-Escalante, J. J., \& Silveira, C. A. (2007). Prevalence and bacterial susceptibility of community acquired urinary tract infection in University Hospital of Brasília, 2001 to 2005. Revista Da Sociedade Brasileira de Medicina Tropical, 40(6), 643-647. https://doi.org/10.1590/s0037-86822007000600009

Squadrito, F. J., \& del Portal, D. (2017). Nitrofurantoin.

Tandogdu, Z., \& Wagenlehner, F. M. E. (2016). Global epidemiology of urinary tract infections. Current Opinion in Infectious Diseases, 29(1), 73-79. https://doi.org/10.1097/QCO.0000000000000228

Thabit, A. K., Crandon, J. L., \& Nicolau, D. P. (2015). Antimicrobial resistance: Impact on clinical and economic outcomes and the need for new antimicrobials. Expert Opinion on Pharmacotherapy, 16(2), 159-177. https://doi.org/10.1517/14656566.2015.993381

Wang, J. Y., Liao, L., Liu, M., Sumarsono, B., \& Cong, M. (2018). Epidemiology of lower urinary tract symptoms in a cross-sectional, population-based study the status in China. Medicine (United States), 97(34). https://doi.org/10.1097/MD.0000000000011554 